Journal of Applied Pharmaceutical Science Vol. 5 (10), pp. 132-135, October, 2015

Available online at http://www.japsonline.com

DOI: $10.7324 / \mathrm{JAPS} .2015 .501022$

ISSN 2231-3354 (cc) BY-NC-sA

\title{
Evaluation of Sodium Carboxymethyl Starch obtained from Ipomoea Batatas
}

\author{
Mohammed Achor*, James Yinka Oyeniyi, mahmud sani gwarzo, Aminu Zayyanu \\ Faculty of Pharmaceutical Sciences, Usmanu Danfodiyo University, Sokoto, Nigeria.
}

\begin{tabular}{|c|c|}
\hline ARTICLE INFO & ABSTRACT \\
\hline Article & \multirow{8}{*}{$\begin{array}{l}\text { The study sought to evaluate the functional properties of sodium carboxymethyl starch obtained from Ipomoea } \\
\text { batatas, in order to facilitate their exploitation as substitute excipients for the local pharmaceutical manufacturing } \\
\text { industry. The sodium carboxymethyl starch was produced by reacting native starch with sodium hydroxide and } \\
\text { sodium monochloroacetate in various proportions and reaction time at constant temperature. Subsequently, the } \\
\text { starches were obtained by wet separation techniques. Physicochemical properties and proximate analysis were } \\
\text { carried out in order to determine their suitability for pharmaceutical use. Differences in the physicochemical } \\
\text { properties, proximate composition, and functional properties of sodium carboxymethyl starches and native } \\
\text { Ipomoea batatas starch were significant. Optimum degree of substitution and reaction efficiency of } 0.52 \text { and } \\
1.92 \% \text { were achieved when sodium hydroxide and sodium monochloroacetate in a ratio } 1.5 \text { and } 2.0 \text { Mole per } \\
\text { anhydrous glucose unite respectively in } 6 \text { hrs was used. Generally, the carboxymethyl starches had higher bulk } \\
\text { density, tapped density, true density, hydration and swelling capacity as compared to the native starch. }\end{array}$} \\
\hline Received on: $24 / 11 / 2014$ & \\
\hline & \\
\hline & \\
\hline Available online: $28 / 10 / 2015$ & \\
\hline Key words: & \\
\hline Ipomoea batatas, sodium & \\
\hline $\begin{array}{l}\text { carboxymethyl starch, } \\
\text { sodium monochloroace }\end{array}$ & \\
\hline
\end{tabular}

\section{INTRODUCTION}

The use of natural starch and its derivatives as biodegradable polymers continue to be an area of active research despite the advent of synthetic polymers. It does remain attractive, primarily because they are inexpensive, readily available, degradable, biocompatible and non-toxic (Nikazar et al., 2005; Yaacob, et al., 2011). Recently, natural starch has increasingly gained importance as a backbone for new biopolymer material and functional polymer mainly synthesized by chemical modification reactions (Abdulmajid et al., 2010). Carboxymethylation process of starch is one of the most versatile functionalization procedures as it provides access to biomaterials with valuable properties. The alterations take place at the molecular level with little or no change taking place in the superficial appearance of the granule. Sweet potato (Ipomoea batatas) is adaptable to a broad range of agro-ecological conditions and fits into low-input agriculture. It is highly productive even under adverse farming conditions (Prakash, 1994). Sweet potato is cultivated in more than 100 countries as a

\footnotetext{
* Corresponding Author

MOHAMMED ACHOR, Faculty of Pharmaceutical Sciences,

Usmanu Danfodiyo University, Sokoto, Nigeria.

Email: munchors001@yahoo.com
}

valuable source of human food, animal feed and industrial raw material. The objective of this study is to evaluate sodium carboxymethyl starch obtained from Ipomoea batatas as an excipient for pharmaceutical applications.

\section{MATERIALS AND METHODS}

\section{Materials}

The root tubers of Ipomoea batatas were obtained from Sokoto central market, Sokoto state, Nigeria. All other chemicals and reagents used were of analytical grade.

\section{Methods \\ Extraction}

The procedure described by Alves et al. (2002) was adopted with little modification. The tubers were peeled and cut into cube. These cubes were then soaked in 10 liters $0.075 \%$ of sodium metabisulphite solution overnight. This mixture was then milled, stirred and filtered using double fold clean cheesecloth which was allowed to completely settle while the starch sediments. This was followed by decanting the water and centrifuging the suspension at $4000 \mathrm{rpm}$ for $5 \mathrm{~min}$ using Lab centrifuge (Thermo electron co. IEC FL40R, France); after centrifugation, the starch was separated from water and non water soluble constituents. 
Finally the pure starch obtained from centrifugation was air dried in a hot air oven (Nurve FN055 Oven, Germany), grinded with a grinder (Super Master Co. Ltd. SMB-3377) and sifted through Sethi standard sieves. The flour was then packed into an airtight container and stored at room temperature for further analysis.

\section{Starch Modification}

Organic slurry method of modification was used as described by Lawal, et al., (2007). The native sweet potato starch $(10.0 \mathrm{~g})$ was suspended in 2-propanol $(200 \mathrm{ml}) .20 \mathrm{ml}$ of aqueous sodium hydroxide solution was added (1.0 M, 1.5 M, and 2.0 M). The mixture was stirred at controlled temperature $\left(40{ }^{\circ} \mathrm{C}\right)$ for 10 min. $80 \mathrm{ml}$ Sodium monochloroacetate of $2.0 \mathrm{M}$ conc. was added and stirring was continued up to the designated time ( $2 \mathrm{hrs}, 4 \mathrm{hrs}$ and $6 \mathrm{hrs}$ ). The $\mathrm{pH}$ of mixture was adjusted to about 5.0 by addition of $50 \%$ glacial acetic acid. The carboxymethyl starch was filtered and washed with $80 \%$ aqueous ethanol until the $\mathrm{pH}$ of liquid becomes neutral (7.0). The modified starch was dried at $50{ }^{\circ} \mathrm{C}$ for $6 \mathrm{hrs}$. The dried carboxymethyl starch was passed through a 100 -mesh sieve.

\section{FT-IR Study}

Both native and carboxymethyl starch sample $(5 \mathrm{mg})$ were blended with solid $\mathrm{KBr}$, (Merck, Germany) and about $40 \mathrm{mg}$ blend was used to prepare a pellet (Hydraulic pellet press KP, Mumbai, India).The spectra were scanned from $4500-250 \mathrm{~cm}^{-1}$ in a Perkin Elmer FT-IR spectrometer(Perkin Elmer, USA) under dry air at room temperature.

\section{Determination of the Degree of Substitution of CMS}

The degree of substitution (DS) was determined with flame atomic absorption spectrometry based on the sodium content of the CMS according to the method describe by Lawal, et al (2009). The sample $(50 \mathrm{mg}$ ) was heated with conc. nitric acid (4 $\mathrm{cm}^{3}$ ) in glass vessel with hot plate. The digestion was made up to $100 \mathrm{~cm}^{3}$ with deionized water. Flame atomic absorption spectrometer was used for the analysis. The flame composition was air-acetylene while the wavelength of sodium was $589.0 \mathrm{~nm}$. The degree of substitution was determined as follows:

$$
\mathrm{DS}=\frac{162 \% N a}{(2300-80 \% N a)}
$$

$\% \mathrm{Na}$ of the unmodified starch was predetermined and it was corrected in the CMS derivative.

\section{Determination of Reaction Efficiency}

Reaction efficiency was determined using the following equation as described by Lawal et al (2008)

$$
\begin{gathered}
\mathrm{RE}=\frac{D S X 100}{D S t} \ldots \ldots \ldots \ldots \text { (2) } \\
\text { Where: } \text { Dst }=\frac{n S M A}{n A G U}, \text { If } \mathrm{nNaOH} \geq \mathrm{nSMCA} \\
\text { Dst }=\frac{n N a O H}{n A G U}, \quad \text { If } n N a O H<n S M C A
\end{gathered}
$$

Nsmca $=$ Number of moles of sodium

monochloroacetate, $\mathrm{nAGU}=$ Number of moles of anhydroglucose unit, $\mathrm{nNaOH}=$ Number of moles of sodium hydroxide.

\section{True density}

The true density $\left(\mathrm{D}_{1}\right)$ of the starch was determined by the liquid displacement method using xylene as the immersion fluid as described by Ohwoauvorhua et al (2004) and computed according to the following equation.

$$
\mathrm{D}_{1}=\mathrm{W} /[(\mathrm{a}+\mathrm{w})-\mathrm{b}] \mathrm{x} \mathrm{SG}
$$

Were $w$ is the weight of the powder, SG is specific gravity of liquid, a, is Weight of bottle + liquid and b is weight of bottle + solvent + powder.

\section{Bulk and tapped densities}

A $10 \mathrm{~g}$ quantity of the powder sample was Placed in 50 $\mathrm{ml}$ clean, dry measuring cylinder and the volume $\mathrm{V}_{\mathrm{o}}$ occupied by the sample without tapping determined. After 500 manual taps, occupied volume V500 was determined. The bulk and tapped densities was calculated as the ratio of the weight of weight of volume $\left(\mathrm{V}_{\mathrm{o}}\right.$ and $\mathrm{V}_{500}$ respectively). The Carr's index and Hausner's ratio were determined from the values of the bulk and tapped densities results obtained above.

\section{Powder porosity}

This was determined from the values of true and bulk densities when fitted into the equation according to the method of Ohwoauvorhua et al (2004):

$\mathrm{e}=1-\mathrm{B}_{\mathrm{b}} / \mathrm{D}_{\mathrm{t}} \times 10$

Were $\mathrm{Bb}$, is the bulk density, $\mathrm{D}$, is the true density and $\mathrm{e}$ is the porosity

\section{Hydration capacity}

The method of Kornblum and stoopak (1973) was used. A $1 \mathrm{~g}$ sample was placed in each of four $15 \mathrm{ml}$ plastic centrifuge tubes and $10 \mathrm{ml}$ distilled water added from a $10 \mathrm{ml}$ measuring cylinder and then stopped. The contents were mixed on a vortex mixer for $2 \mathrm{~min}$. The mixture then allowed to stand for $10 \mathrm{~min}$ and immediately centrifuged. The supernatant was carefully decanted and the sediment weighed. The hydration capacity was taken as the ratio of the weight of the sediment to the dry sample weight.

\section{Swelling capacity}

This was determined at the same time as the hydration determination using the method of Okhamafe et al (1991) and computed according to the following equation;

$\mathrm{S}=\left(\mathrm{V}_{2}-\mathrm{V}_{1}\right) / \mathrm{V}_{1} \times 100 \%$

Where $\mathrm{S}$ is the \% swelling capacity, $\mathrm{V}_{2}$ is the volume of the hydration or swollen material and $V_{1}$ is the tapped volume of the material prior to hydration.

\section{Proximate and Elemental analysis}

The proximate analysis for moisture, crude protein, crude lipid, fiber and ash content of native and retrograded starches were carried out according to the method of the AOAC (1990). The conversion factor of total nitrogen to crude protein was 6.25 . Percentage total carbohydrate was determined by subtracting the 
sum total of ash, crude protein, lipid and fiber from 100. The elemental analysis was carried out using an atomic absorption spectrophotometer.

\section{RESULTS AND DISCUSSION}

The addition of carboxyl group is indicated by presence of an absorption peak band at 3875 in the FT-IR spectrum of sodium CMS which is not present in native starch (Fig. 1).

Increase in the amount of $\mathrm{NaOH}$ favorably increases both the DS and reaction efficiency. The limitation observed as the concentration of $\mathrm{NaOH}$ increases in the reaction mixture can be explain based on two competing reaction during the carboxymethylation process. Firstly, the $\mathrm{NaOH}$ provides the alkaline environment for the reaction as well as serving as the swelling agent to facilitate diffusion and penetration of the etherifying agent to starch granular structure and secondly, further increase in $\mathrm{NaOH}$ concentration causes an inactivation of sodium monochloroacetate and hence consumed in the side reaction (Lawal et al., 2008).

Table 1: Parameters for Starch Modifications.

\begin{tabular}{ccccc}
\hline Samples & NaOH(M) & SMCA(M) & Time (hrs) & Temp. $\left({ }^{\mathbf{0}} \mathbf{C}\right)$ \\
\hline SP1 & 1.0 & 2.0 & 2.0 & 40 \\
SP2 & 1.5 & 2.0 & 2.0 & 40 \\
SP3 & 2.0 & 2.0 & 2.0 & 40 \\
SP4 & 1.0 & 2.0 & 4.0 & 40 \\
SP5 & 1.5 & 2.0 & 4.0 & 40 \\
SP6 & 2.0 & 2.0 & 4.0 & 40 \\
SP7 & 1.0 & 2.0 & 6.0 & 40 \\
SP8 & 1.5 & 2.0 & 6.0 & 40 \\
SP9 & 2.0 & 2.0 & 6.0 & 40 \\
\hline
\end{tabular}

Both RE and DS (Table 2) increased with increase in reaction time within the time frame studied. The increase in the DS and $\mathrm{RE}$ with increase time is as a result of enhanced period of contact of etherifying reagent with the starch molecules. However no remarkable further increases were observed in both DS and RE after $4 \mathrm{hrs}$ of reaction. The Swelling power of the starches increased with starch modification. This may be due to water penetrating into the starch granules as a result of the hydrophilic nature of carboxymethyl groups. Similarly, carboxymethyl starch had high hydration capacity as compared to native starch. This may be due to addition of negatively charged carboxymethyl group to starch.

Table 2: Material Properties of Native and Sodium Carboxymethyl Starches.

\begin{tabular}{ccccc}
\hline Samples & $\begin{array}{c}\text { Degree of } \\
\text { Substitution }\end{array}$ & $\begin{array}{c}\text { Reaction } \\
\text { Efficiency (\%) }\end{array}$ & $\begin{array}{c}\text { Swelling } \\
\text { Capacity(\%) }\end{array}$ & $\begin{array}{c}\text { Hydration } \\
\text { Capacity (\%) }\end{array}$ \\
\hline SP1 & 0.07 & 0.41 & 25.00 & 1.80 \\
SP2 & 0.41 & 1.52 & 42.86 & 1.87 \\
SP3 & 0.14 & 0.40 & 42.86 & 1.85 \\
SP4 & 0.14 & 0.78 & 42.86 & 1.84 \\
SP5 & 0.11 & 0.41 & 28.57 & 1.81 \\
SP6 & 0.10 & 0.26 & 28.57 & 1.80 \\
SP7 & 0.16 & 0.88 & 42.86 & 1.86 \\
SP8 & 0.52 & 1.92 & 53.85 & 1.96 \\
SP9 & 0.14 & 0.38 & 33.33 & 1.81 \\
Native & -- & -- & 12.50 & 1.70 \\
\hline
\end{tabular}

The physical properties showed little or no significant differences in bulk and flow properties between the native starch and carboxymethyl derivative but higher powder porosity of the carboxymethyl derivatives as compared to native starch (Table 3 ). The proximate composition is a major determinant of starch purity. It determines the presence of all other contaminants or impurities other than pure starch. Residual moisture content of starches from the native and carboxymethyl derivative were less than $15 \%$, which is the upper limit recommended by the British Pharmacopoeia, 2010 (Table 4). The ash content of the native starch investigated were less than $0.6 \% \mathrm{w} / \mathrm{w}$ while the ash content of carboxymethyl derivatives were mostly higher (Table 4). This might be due to the impurities contributed by the reagents used during modification. The Carboxymethyl derivative had lower lipid content and higher crude protein as compared to the native starch. From the results as seen in Table 5, there was no significant difference between calcium, magnesium and phosphorus but an increase in sodium and potassium with starch modification. Presence of inorganic salts and ions of phosphorous, sodium, iodine and hydroxyl groups in starch have been reported to contribute significantly to starch granule swelling and gelatinization (Mistry and Eckhoff, 1992).

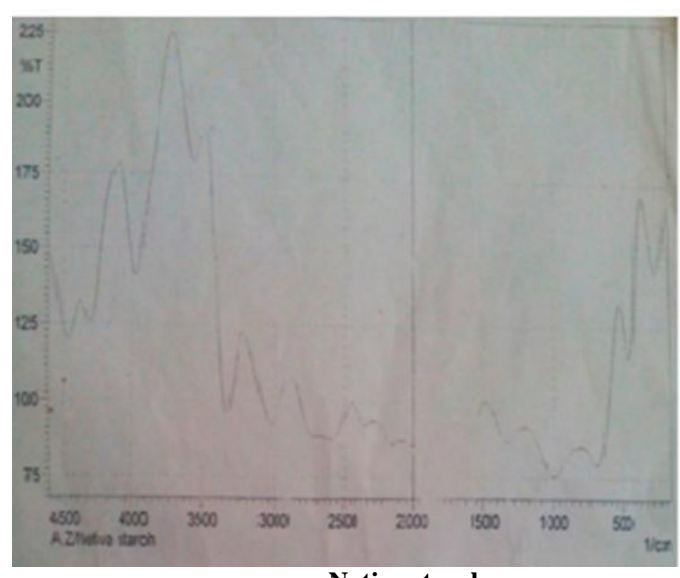

Native starch

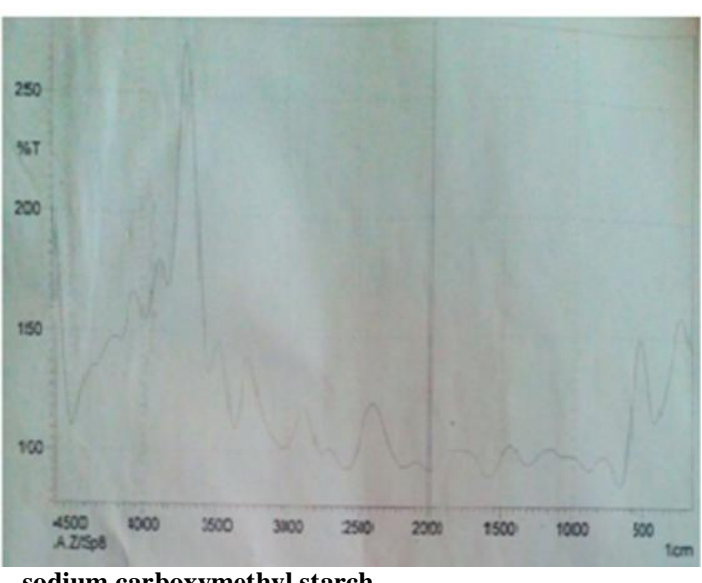

sodium carboxymethyl starch

Fig. 1: FTIR Spectra of native and sodium carboxymethyl starch. 
Table 3: Physicochemical Parameters of Native and Sodium Carboxymethyl Starches.

\begin{tabular}{|c|c|c|c|c|c|c|}
\hline Samples & Bulk Density (g/ml) & $\begin{array}{c}\text { Tapped Density } \\
(\mathrm{g} / \mathrm{ml})\end{array}$ & Carr's Index & Hausner's Ratio & $\begin{array}{c}\text { True Density } \\
\left(\mathrm{g} / \mathrm{cm}^{3}\right)\end{array}$ & Powder Porosity \\
\hline SP1 & 0.57 & 0.79 & 0.22 & 1.38 & 3.28 & 8.26 \\
\hline SP2 & 0.55 & 0.82 & 0.27 & 1.50 & 3.14 & 8.26 \\
\hline SP3 & 0.53 & 0.76 & 0.23 & 1.50 & 2.54 & 7.92 \\
\hline SP4 & 0.51 & 0.75 & 0.24 & 1.47 & 2.50 & 7.95 \\
\hline SP5 & 0.58 & 0.84 & 0.26 & 1.41 & 2.71 & 7.95 \\
\hline SP6 & 0.58 & 0.80 & 0.22 & 1.39 & 3.14 & 8.16 \\
\hline SP7 & 0.55 & 0.83 & 0.28 & 1.50 & 2.86 & 8.07 \\
\hline SP8 & 0.43 & 0.81 & 0.38 & 1.87 & 1.95 & 7.77 \\
\hline SP9 & 0.65 & 0.91 & 0.26 & 1.41 & 2.83 & 7.72 \\
\hline Native & 0.61 & 0.84 & 0.23 & 1.31 & 2.50 & 7.55 \\
\hline
\end{tabular}

Table 4: Proximate Analysis of Native and sodium Carboxymethyl Starches.

\begin{tabular}{|c|c|c|c|c|c|c|c|}
\hline Samples & $\begin{array}{c}\text { Moisture Content } \\
(\%)\end{array}$ & $\operatorname{Ash}(\%)$ & Nitrogen (\%) & $\begin{array}{c}\text { Crude Protein } \\
(\%)\end{array}$ & Lipid (\%) & $\begin{array}{c}\text { Fiber } \\
(\%)\end{array}$ & $\begin{array}{c}\text { Carbohydrate } \\
(\%)\end{array}$ \\
\hline SP1 & 5.05 & 0.10 & 0.57 & 3.59 & 0.05 & 0.05 & 96.21 \\
\hline SP2 & 5.50 & 0.33 & 0.57 & 3.59 & 0.45 & 0.05 & 95.58 \\
\hline SP3 & 4.00 & 0.86 & 0.38 & 2.36 & 0.05 & 0.05 & 96.68 \\
\hline SP4 & 4.75 & 0.86 & 0.50 & 3.24 & 0.30 & 0.05 & 95.55 \\
\hline SP5 & 4.70 & 0.93 & 0.55 & 3.41 & 0.05 & 0.05 & 95.56 \\
\hline SP6 & 5.50 & 0.96 & 0.52 & 3.24 & 0.05 & 0.05 & 95.70 \\
\hline SP7 & 4.30 & 0.36 & 0.50 & 3.24 & 0.50 & 0.05 & 95.85 \\
\hline SP8 & 4.55 & 0.81 & 0.50 & 3.24 & 0.15 & 0.05 & 95.75 \\
\hline SP9 & 4.35 & 0.58 & 0.60 & 3.76 & 0.10 & 0.05 & 95.51 \\
\hline Native & 9.25 & 0.05 & 0.42 & 2.63 & 0.55 & 0.05 & 96.72 \\
\hline
\end{tabular}

Table 5: Elementary Analysis of Native and Sodium Carboxymethyl Starches.

$\left.\begin{array}{ccccc}\hline \text { Samples } & \begin{array}{c}\text { Sodium } \\ (\mathbf{m g} / \mathbf{K g})\end{array} & \begin{array}{c}\text { Potassium } \\ (\mathbf{m g} / \mathbf{K g})\end{array} & \begin{array}{c}\text { Calcium } \\ (\mathbf{m g} / \mathbf{K g})\end{array} & \begin{array}{c}\text { Magnesium } \\ (\mathbf{m g} / \mathbf{K g})\end{array} \\ \hline \text { SP1 } & 132.0 & 110.5 & 0.35 & 0.25 \\ (\mathbf{m g} / \mathbf{K g})\end{array}\right)$

\section{CONCLUSION}

Sodium carboxymethyl starch derived from Ipomoea batatas would be a suitable alternative to other native and modified starches commonly used in pharmaceutical preparations.

\section{REFERENCES}

Abdul Majid RH, Mat Taib R. Effects of polyethylene- $g$-maleic anhydride on properties of low density polyethylene/thermoplastic sago starch reinforced kenaf fibre composites, Iran Polym J, 2010; 19: 501-510.

Alves RM, Grossmann MV, Ferrero C, Zaritzky NE, Martino MN, Sierakoski MR. Chemical and functional characterization of products obtained from yam tubers. Starch, 2002; 54: 476-481.

Association of analytical chemist. Official methods of analysis of AOAC international (16 ${ }^{\text {th }}$ Ed.). Gaithsburg, ML: Association of analytical chemist International. 1990

British Pharmacopoeia. Her Majesty's Stationary Office, University Press, Cambridge. 2010

Kornblum SS, Stoopak SB. A new tablet disintegrating agent: crosslinked polyvinyl pyrolidine. J. Pharm. Sci., 1973; 62(i):43-48

Lawal OS, Lechner MD, Hartmann B, Kulicke WM. Carboxymethyl cocoyam starch: synthesis, characterization and influence of the reaction parameters. Starch/Sta"rke, 2007; 59: 224 - 233

Lawal OS, Lechner MD, Kulicke WM. Single and multistep carboxymethylation of water yam (Dioscrea alata) starch: synthesis and characterization. Int. J. Biol. Macromol, 2008; 42: 429-435
Lawal OS, Storz H, Lohman D, Lechner D, Kulicke WM. Hydrogels based on carboxymethyl cassava starch cross linked with di- or polyfunctional carboxylic acids: synthesis, water absorbent behavior and rheological characterizations. European Polymer Journal, 2009;45:33993408

Mistry AH, Eckhoff SR. Characterization of alkali extracted starch obtained from corn flour. Cereal Chem, 1992; 69: 296 - 303

Nikazar M, Safari B, Bonakdarpour B, Milani Z. Improving the biodegradability and mechanical strength of corn starch-LDPE blends through formulation modification. Iran Polym J, 2005; 14:1050-1057

Ohwoavworhua FO, Kunle OO, Ofoefule SI. Extraction and characterization of microcrystalline cellulose derived from Luffa cylindrical plant. Afri. J. Pharm. Res. Dev. 2004; 1 (1):1-6

Okhamafe AO, Igboechi A, Obaseki TO. Celluloses extracted from groundnut shell and rice husk, preliminary physicochemical characterization. Pharm World J. 1991; 8(4):120-130

Prakash CS. Sweet potato biotechnology: progress and potential. Biotech. and Dev. Monitor, 1994; 18:1919-1822

Yaacob B, Amin MCIM, Hashim K, Bakar BA. Optimization of reaction conditions of caroxymethylated sago starch. Iran Polym J, 2011; 20:195-204

\section{How to cite this article:}

Mohammed Achor, James Yinka Oyeniyi, mahmud sani gwarzo, Aminu Zayyanu. Evaluation of Sodium Carboxymethyl Starch obtained from Ipomoea Batatas. J App Pharm Sci, 2015; 5 (10): 132-135. 